\title{
Beyond Diversity and Inclusion: Reparative Justice in Medical Education
}

\author{
J. Corey Williams ${ }^{1} \cdot$ Nientara Anderson ${ }^{2} \cdot$ Dowin Boatright $^{2}$ \\ Received: 18 February 2020 / Accepted: 17 December 2020 / Published online: 7 January 2021 \\ (C) Academic Psychiatry 2021
}

Despite the strenuous efforts of academic medical centers in the USA, groups identified as underrepresented in medicine (URM) have remained underrepresented in medicine. For the past few decades, these efforts to increase the number of URM students, trainees, and physicians have focused on "diversity and inclusion." This framework, as mandated by LCME (Liaison Committee Medical Education) standards for diversity, has historically emphasized various strategies such as increasing recruitment of URMs from existing applicant pools, pipeline and mentorship programs, and holistic review practices.

While recruitment and representation efforts are critical, they do not adequately address the structural racism that underlies the limited applicant pool of URMs or the retention of URMs in academic medicine. We argue that academic medical centers should move beyond traditional diversity and inclusion frameworks to a reparative justice framework that acknowledges the history of American medical institutions perpetrating and benefiting from structural racism. Through reparative justice frameworks, minority trainees, faculty, and staff will not only be represented at their home institutions but will also experience true acknowledgement and sincere efforts to redress the history of racism in medicine.

In this Commentary, we will (1) define a reparative justice framework, (2) provide a brief historical context of the systemic racism in American medicine that necessitates reparative justice, and (3) explore concrete examples of reparative justice in academic learning environments to address issues of underrepresentation and poor retention of minority groups.

J. Corey Williams

jwilli17@gmail.com

1 Medstar-Georgetown University Hospital, Washington, DC, USA

2 Yale-New Haven Hospital, New Haven, CT, USA

\section{What is Reparative Justice?}

A reparative justice framework has been used by international human rights organizations to create more just and equitable environments for populations attempting to heal from violence and oppression. A reparative justice framework seeks to repair the harm done to victims of human rights violations. Reparative justice focuses on three principles: first is the acknowledgement of specific victims. This includes institutional recognition of the moral and/or legal obligation to officially recognize and redress wrongdoing. Second is taking concrete, substantive steps to repair harms the victims have suffered. Third is validating victims as intrinsic rights-bearers [1]. We acknowledge that this framework is not independent of other frameworks such as restorative justice, which has been used to address hurtful or disruptive incidents that erode institutional climate. Reparative justice can be used to expand existing efforts to improve institutional climate and diversify the medical pipeline.

To operate within a reparative justice framework, American medical institutions must acknowledge the historical injustices in which they participated and from which they continue to benefit, as well as the victims of those injustices. They must then take active steps to repair the consequences of those injustices. Finally, they must validate URMs as rightsbearing members of the institution, entitled to the same rights, freedoms, and advantages afforded to the dominant group. Implementing such a framework would expand both recruitment and retention of URMs in medicine, thus improve quality of care for marginalized patients [2].

\section{Historical Context}

White physicians and medical institutions played a major role in the creating America's racial caste system beginning in the age of European colonization and chattel slavery [3]. Responsible for keeping human cargo alive on slavers' ships, physicians were so 
integral to the slave trade that they were often the highest paid person onboard other than the captain, and some received portions of proceeds from the sale of enslaved African people [4]. Physicians were also active in the appraisal of slaves during auctions to verify sound health of the slave and legitimize the monetary value of the slave [5]. Many leading academic medical centers in the USA were built with slave labor or profits derived from the sale of enslaved people [6]. In addition, as selfproclaimed experts on "Negro Medicine," early white colonial physicians helped to justify the brutal practices of slavery. Physicians also conducted unspeakably violent experimentation on Black people, a practice that extended from the era of chattel slavery into the twentieth century [7].

After emancipation, the AMA (American Medical Association), America's largest professional organization for physicians, systematically excluded African-American physicians, deliberately hindering their ability to practice medicine [8]. Funded by the Carnegie Foundation, the AMA commissioned the Flexner report with the explicit intention of limiting membership in the medical profession. After its publication in 1910, the implementation of the Flexner report's recommendations directly precipitated the dissolution of four out of six historically Black medical colleges including Leonard Medical School, the largest Black medical school, causing a precipitous drop in the number of Black doctors in the USA $[9,10]$. These Black medical colleges and their aspiring Black students fell victim to the structurally racist policies and practices of the AMA and Carnegie Foundation allowing American medical schools to more seamlessly populate their student bodies and leadership roles with predominantly white students for decades. In psychiatry, for example, the American Psychiatric Association (APA) during the 1960s was criticized for its lack of minority representation among its membership and exclusion of Black psychiatrists on leadership counsels and committees [11].

The legacy of historical exclusion and oppression has persisted to the present day as the underrepresentation of certain groups continues in medicine. Modest progress has resulted from various efforts such as the LCME diversity and inclusion accreditation standards, and the development of AAMC Group on Diversity and Inclusion and the AAMCC Group on Women in Medicine and Science [12]. However, the admission to medical school remains deeply skewed towards white, well-resourced applicants, while many minority students lack the wealth, resources, educational opportunities, and social connections necessary to gain entrance to medical school [13]. While many existing diversity and inclusion efforts are worthwhile, these initiatives should be augmented with initiatives that operate under a reparative justice framework. Reparative justice measures will necessarily vary from institution to institution depending on their specific histories.

First and foremost, medical institutions and large professional organizations in the USA need to openly acknowledge these specific historic wrongs and their victims, whether they be specific individuals, Black physicians in general, or Black medical colleges. Then, in order to take active steps to repair these wrongs and validate URMs as intrinsic rights-bearers, leadership in professional organizations needs to sponsor, mandate, and support academic leadership to comprehensively examine the structural racism embedded in all aspects of their departments including recruitment, admissions processes, research practices, artwork in public spaces, curriculum, and clinical care, to name a few. We will discuss how a reparative justice framework could be implemented in a few of these areas.

\section{An Example of Reparative Justice in Academia}

In one widely reported example, students from Georgetown University proposed arguably one of the most progressive policies to date as their explicitly reparative efforts sought to describe how the institution benefited from slavery and racial injustice and to identify the victims of these historical atrocities. When information surfaced that the sale of 272 slaves in 1838 saved the Georgetown from financial catastrophe, the University delivered an official apology. A workgroup was assembled that wrote, "we are convinced that reparative justice requires a meaningful financial commitment from the University." In a student-led referendum, students voted to tax themselves to create a fund that will support the descendants of the enslaved people from whom the University profited. Furthermore, the descendants of the 272 enslaved people have been given free admissions into the University [14]. Although not directly related to medicine, this initiative should serve as an exemplar initiative that challenges medical schools and academic departments to examine their specific historical connection to slavery and historical atrocities and seek to repair the lasting effects.

\section{Potential Applications in Academic Medicine}

Disparities of educational opportunities between whites and other minority groups begin in the early childhood period and accumulate over the life course. Recent research also shows that, even when they keep pace with whites academically, and regardless of socioeconomic status (SES), URMs' likelihood of educational advancement diminishes with each progressive stage of higher education $[15,16]$. Given these structural barriers that URMs face early in life, a reparative justice framework is particularly important in recruitment practices and should be used to expand pre-existing diversity and inclusion efforts.

\section{Pipeline Programs}

In a traditional diversity and inclusion framework, pipeline programs have mainly comprised of summer enrichment 
programs and mentorship for select college and medical students. Reparative justice frameworks should augment these efforts to the address centuries of exclusion and racial violence. Pipeline programs need be race-conscious to target investment in specific minority communities. Programs should start during early education and be integrated into mentorship, support, and financial assistance programs that follow URM students throughout high school, college, medical school, residency, and even junior faculty positions. Academic institutions can form partnerships with local public schools to select and support young students who show academic promise, and critically, provide free tuition for those that matriculate. Beyond individual students, a reparative justice framework could include a broader financial commitment from the university to invest in local schools, housing, and employment. While existing pipeline programs have shown some success at different levels of training [17], reparative justice compels institutions to go a step further and address underlying societal barriers that begin early in life.

\section{Admissions Committees}

Beyond simply diversifying the applicant or candidate pool, a reparative framework applied to recruitment must also include more URMs as interviewers, admissions officers, and on hiring committees. Official guidelines already recommend the inclusion of women and URMs in order to improve diversity in admissions and hiring decisions [18]. A reparative justice framework, however, considers going beyond mere inclusion, and leans towards a majority of women and URMs on admissions and hiring committees in an attempt to repair a history of disproportionate representation of men and white people. Existing evidence supports this approach, especially considering that there is evidence that African-American physicians tend to have less implicit racial bias than White, Asian, or Hispanic physicians, and that women and racial minorities have less implicit bias than their white male counterparts [19]. Furthermore, in simulated admission scenarios, URM officers are more likely to choose applicants from low SES backgrounds and are less likely to prefer white candidates than non-URM admissions officers [20]. Research also supports having separate diversity committees with URM faculty that review the self-identified URM applicants first to determine interview invitations [21].

\section{Application Review}

In terms of applicant review and selection, the AAMC recommends a holistic review process of evaluating experiences, attributes, metrics, and competencies [22]. Under a reparative justice framework, admission committees need to formalize their holistic review process to value an applicant's background, lived experiences of diversity and discrimination, and applicants who have demonstrated commitment to communities of color. This framework can be formally shaped to weigh lived experiences of URMs through a reparative lens. These experiences might also include growing up in structurally oppressed communities of color, attending an HBCU (Historically Black Colleges and Universities), and demonstrating commitment to racial justice. These experiences and attributes should carry more weight than prestigious AOA (i.e., medical honor society) membership, for example, which has been shown to be racially biased [23], and USMLE scores which disadvantage URM students [24].

\section{The Interview Day}

Existing research suggests that URM applicants use the interview day to gauge how well they will "fit in" racially and culturally at a given program and that this assessment factors highly into how they rank residency programs [25]. In addition to increasing the number of URM medical students, residents, and faculty and making them more visible during interview days, programs can also apply a reparative justice framework to the language used, topics covered, and questions asked during interviews [26]. During interview days, we argue that the language of diversity and inclusion is often evoked to address candidate's concerns for racial climate. However, this terminology is vague and broad, often washing over specific issues of racism, which are seldom addressed during interview days. A reparative framework would include frankly recognizing and taking responsibility for any current deficits in URM representation, openly acknowledging any institutional racial history and clearly providing evidence of commitment to antiracist and reparative practices.

\section{Visual Culture}

Although medical schools may diversify their students and faculty, hallways dominated by portraits of white men mark these institutions as predominantly white spaces [27]. A reparative justice framework mandates attempts to reform the visual culture in order to convey an institutional willingness to confront fraught histories of racial violence. Therefore, Art in public space committees should be formed and charged with reimagining the visual culture of the institution. Such committees should represent all stakeholders including faculty, trainees, staff, and patients. These initiatives should be undertaken in order to celebrate the minorities who are currently part of these institutions and provide them a sense of affirmation, safety, belonging, and freedom of cultural expression. Furthermore, visual culture reforms help redress the historic 
exclusion of URMs from academic medicine. Many educational institutions have already begun this process, resulting in the removal of portraits of white men, and the addition of portraits of women or minorities [28-30]. These initiatives are not an "erasure" of history; rather, they are attempts to represent history more completely, and in a way that accounts for the perspective of minorities.

\section{Conclusion}

The recommendations above should, of course, be supplemental to other structural changes - such as improved financial aid, better mental health resources, mentorship programs, and academic support - that are widely accepted to improve URM and minority student success in higher education [13, 31]. If academic departments wish to recruit and retain their underrepresented minority employees, the idea of reparative justice - rather than vague notions of "diversity" - is critical. As author Ta-Nehisi Coates wrote, "America was built on the preferential treatment of white people-395 years of it. Vaguely endorsing a cuddly, feel-good diversity does very little to redress this" [32]. Accordingly, academic medical centers will never close the racial and ethnic gaps in representation, advancement, and empowerment within their institutions until they push beyond diversity and inclusion and embrace the need for reparative justice.

\section{Compliance with Ethical Standards}

Conflict of Interest On behalf of all authors, the corresponding author states that there is no conflict of interest.

\section{References}

1. International Center for Transitional Justice. Reparations. [Cited 2020 January 25]. Available from: https://www.ictj.org/our-work/ transitional-justice-issues/reparations. Accessed 12 Jan 2020.

2. Cohen JJ, Gabriel BA, Terrell C. The case for diversity in the health care workforce. Health Aff. 2002;21(5):90-102.

3. Turner S. Slavery and the production, circulation, and practice of medicine. Soc Hist Med. 2018;31(4):870-6.

4. Halperin EC. Lessons from a slave doctor of 1841. Pharos Alpha Omega Alpha Honor Med Soc. 2013;76(1):10-6.

5. Haller JS. The Negro and the southern physician: a study of medical and racial attitudes 1800-1860. Med Hist. 1972;16(3):238-53.

6. Fabian A. The skull collectors: race, science, and America's unburied dead. Chicago, Illinois: University of Chicago Press; 2010.

7. Washington HA. Medical apartheid: The dark history of medical experimentation on Black Americans from colonial times to the present. New York, NY: Doubleday Books; 2006.

8. Baker RB, Washington HA, Olakanmi O, Savitt TL, Jacobs EA, Hoover E, et al. African American physicians and organized medicine, 1846-1968: origins of a racial divide. JAMA. 2008;300(3): 306-13.
9. Markowitz GE, Rosner DK. Doctors in crisis: a study of the use of medical education reform to establish modern professional elitism in medicine. Am Q. 1973;25(1):83-107.

10. Bailey M. The Flexner report: standardizing medical students through region-, gender-, and race-based hierarchies. Am J Law Med. 2017;43(2-3):209-23.

11. Lightfoot OB, Fields DL. Black psychiatrist of 1969 survey the scene, then and now. In: Griffith EE, Jones BE, Stewart AJ, editors. Black mental health: patients, providers, and systems. Washington, DC: American Psychiatric Pub; 2018. p. 39-52.

12. Boatright DH, Samuels EA, Cramer L, Cross J, Desai M, Latimore $\mathrm{D}$, et al. Association between the liaison committee on medical education's diversity standards and changes in percentage of medical student sex, race, and ethnicity. JAMA. 2018;320(21):2267-9.

13. Smedley BD, Butler AS, Bristow LR. Institute of Medicine (US). Committee on Institutional and Policy-Level Strategies for Increasing the Diversity of the US Health Care Workforce, Institute of Medicine (US), Board on Health Sciences Policy. In the nation's compelling interest: ensuring diversity in the healthcare workforce. Board on Health Sciences Policy. In the nation's compelling interest. Washington, DC. National Academies Press. 2004.

14. Desai S. The first reparations attempt at an American college comes from its students. The Atlantic. 2019. Education. Available from: https://www.theatlantic.com/education/archive/2019/04/why-aregeorgetown-students-paying-reparations/587443/. Accessed 10 Jan 2020.

15. Carnevale AP, Strohl J. Separate and unequal: how higher education reinforces the intergenerational reproduction of white racial privilege. Georgetown University. Public Policy Institute Center on Education and the Workforce. 2013. Available from: https:// cew.georgetown.edu/cew-reports/separate-unequal/. Accessed 15 January 2020

16. Carnevale AP, Fascules ME, Quinn MC, Campbell KP. Born to win, schooled to lose: why equally talented students don't get equal chances to be all they can be. 2019. Georgetown University. Public Policy Institute Center on Education and the Workforce. Available from: https://cew.georgetown.edu/cew-reports/schooled2lose/. Accessed 15 January 2019.

17. Daley S, Wingard DL, Reznik V. Improving the retention of underrepresented minority faculty in academic medicine. J Natl Med Assoc. 2006;98(9):1435-40.

18. Addams AN, Bletzinger RB, Sondheimer HM, White SE, Johnson LM. Roadmap to diversity: integrating holistic review practices into medical school admission processes. 2010; Washington, DC: Association of American Medical Colleges. Available from: https://store.aamc.org/downloadable/download/sample/sample id/ 195/. Accessed 22 Jan 2020.

19. Capers Q, McDougle L, Clinchot DM. Strategies for achieving diversity through medical school admissions. J Health Care Poor Underserved. 2018;29(1):9-18.

20. Bowman NA, Bastedo MN. What role may admissions office diversity and practices play in equitable decisions? Res High Educ. 2018;59(4):430-47.

21. Tunson J, Boatright D, Oberfoell S, Bakes K, Angerhofer C, Lowenstein $\mathrm{S}$, et al. Increasing resident diversity in an emergency medicine residency program: a pilot intervention with three principal strategies. Acad Med. 2016;91(7):958-61.

22. Witzburg RA, Sondheimer HM. Holistic review-shaping the medical profession one applicant at a time. N Engl J Med. 2013;368(17):1565-7.

23. Boatright D, Ross D, O'Connor P, Moore E, Nunez-Smith M. Racial disparities in medical student membership in the Alpha Omega Alpha Honor Society. JAMA Intern Med. 2017;177(5): 659-65. 
24. Edmond MB, Deschenes JL, Eckler M, Wenzel RP. Racial bias in using USMLE Step 1 scores to grant internal medicine residency interviews. Acad Med. 2001;76(12):1253-6.

25. Ku MC, Li YE, Prober C, Valantine H, Girod SC. Decisions, decisions: how program diversity influences residency program choice. J Am Coll Surg. 2011;213(2):294-305.

26. Anderson N, Boatright D, Reisman A. Blackface in white space: using admissions to address racism in medical education. J Gen Intern Med. 2020;35(10):3060-2.

27. Fitzsousa E, Anderson N, Reisman A. "This institution was never meant for me": the impact of institutional historical portraiture on medical students. J Gen Intern Med. 2019;34(12):2738-9.

28. Kowalczyk L. In an about-face, hospital will disperse portraits of past white male luminaries, put the focus on diversity. Boston Globe. 2018. Metro. Available from: https://www.bostonglobe. com/metro/2018/06/13/about-face-hospital-will-disperse-portraitspast-white-male-luminaries-put-focus-diversity/ 0pICgbpsw7QoHFFJQQEZOJ/story.html. Accessed 25 Jan 2019.

29. Mitchell S. A case study in portraiture: Stephen Coit's paintings add diversity, context to Harvard's walls. The Harvard Gazette. 2020.
Campus and Community. Available from: https://news.harvard. edu/gazette/story/2020/01/portrait-project-adds-diversity-toharvards-hallowed-walls/. Accessed 20 Jan 2020.

30. Mintz, L., Yorke H. Top UK university to swap portraits of bearded white scholars with wall of diversity. The Telegraph. 2017. Education. Available from: https://www.telegraph.co.uk/ education/2017/07/14/top-uk-university-replaces-busts-portraitsbearded-white-scholars/. Accessed 20 Jan 2020.

31. Bristow LR, Butler AS, Smedley BD. In the nation's compelling interest: ensuring diversity in the health-care workforce. Institute of Medicine, Board of Health Sciences Policy, Committee on Institutional and Policy- level Strategies for Increasing Diversity of the US Healthcare Workforce. Washington, DC:National Academies Press; 2004. p. 172.

32. Coates TN. The case for reparations. The Atlantic. 2014;313(5):54 71.

Publisher's Note Springer Nature remains neutral with regard to jurisdictional claims in published maps and institutional affiliations. 